\title{
Technological Development of Automation Solutions for the Energy Industry
}

\section{Rodrigo Bueno Otto ${ }^{1 *}$}

https://orcid.org/0000-0003-2303-066X

\section{Carlos Henrique Szollosi ${ }^{1}$}

https://orcid.org/0000-0003-3313-5457

\section{Felipe Lorenzetti ${ }^{1}$}

https://orcid.org/0000-0001-7421-5037

\author{
Felipe Pinheiro da Silva ${ }^{1}$ \\ http://orcid.org/0000-0001-7292-2934
}

Almir Augusto Braggio'

https://orcid.org/0000-0001-8033-2205

\author{
Galileu Godoy Terada² \\ https://orcid.org/0000-0002-5074-2390
}

${ }^{1}$ Itaipu Technological Park Foundation (FPTI), Foz do Iguaçu, Paraná, Brazil; ${ }^{2}$ Itaipu Binacional, Foz do Iguaçu, Paraná, Brazil.

Editor-in-Chief: Alexandre Rasi Aoki

Associate Editor: Alexandre Rasi Aoki

Received: 2021.03.17; Accepted: 2021.05.30.

${ }^{*}$ Correspondence: ottofpti@gmail.com; Tel.: +55-45-35767089 (R.B.O.).

\section{HIGHLIGHTS}

- Characteristics of innovation centers;

- Technology readiness level;

- Product cases developed and positioned in TRL phases;

- Alliances with technology-based companies to provide production and commercialization of technologies.

Abstract: The Innovation Centers are one of the arms of a nation's technological development. Due to their characteristics and objectives, these centers are equipped with laboratories, equipment and researchers capable of developing a product from basic research to the installation of the solution in the field. Entering the context of Innovation Centers and knowing how to correctly position the level of technological maturity is one of the challenges to be understood and explored. In order to advance the market phase, it is recommended to form alliances with technology-based companies to provide both production and commercialization of these technologies, even more if it is possible to create a spinoff from these centers, to take advantage of the experience, knowledge and skills already acquired over time.

Keywords: Technology Readiness Level; R\&D Projects; Technology-based Company.

\section{INTRODUCTION}

Technological evolution has a direct impact on how society lives and develops. Since then, in the last two decades, computers and technical devices have become smaller and smaller due to the advance of information technologies. Along with this, the exchange and processing of data are carried out by using a network that connects the whole world, the internet. Through the interconnection of these facts, this evolution has also reached the areas of industrial production and research and development projects (R\&D) [1]. In 2011, in Germany, the meeting of this technological evolution with the industry was named for the first time 
as "Industrial Revolution 4.0" and in short as "Industry 4.0" [2]. Kagermann [3] point out that the term Industry 4.0 can have two different meanings. The first is the fourth industrial revolution, which occurred after the high advance of electrification, mechanization, and information technologies applied to the industrial area. The second is the labeling of the stance taken by Germany in the elaboration of its strategic plan to strengthen its industrial area.

It is presented by authors, such as Weyer [1] and Wang [4], the importance of adopting the terms of Industry 4.0 as an improvement factor for several industrial processes, mainly, which can improve productivity and economy when aligned with the management process of a respective project. In this sense, several countries worldwide have adopted measures and adjusted their agendas for the adequacy and adoption of the terms proposed by Industry 4.0 Muscio [5]. Following this trend, even though Brazil still lacks several technological advances to accompany the revolution proposed by Industry 4.0 Yamada [6], the country already has an agenda to be followed to follow and carry out such revolution, the "Brazilian Agenda for Industry 4.0" (i4.0) [7].

Following i4.0 [7], the first three industrial revolutions to increased mass production, assembly lines, electricity, and information technology increase the number of tractors and competitors. In this sense, technology is the core of economic development. The i4.0 [7], which will have a more exponential impact, is characterized by a combination of technologies that will allow the fusion of the physical, digital, and biological worlds.

The majority of ITAIPU's equipment technology is from the '70s. Although the lifespan of the barrage and civic structures is estimated at 200 years, electrical and electronic equipment are approaching the end of its operational life. Several of the spare parts are not available in the market, or they are in the process of obsolescence [8].

The Center for Automation and Simulation of Electrical Systems (AS.DT), located in the Itaipu Technological Park (PTI) in Foz do Iguaçu - Paraná - Brazil, has been developing solutions for ITAIPU since 2007. Altogether, 15 solutions have already been delivered to the plant. For example, we have the R\&D of the Disturbance Recorder and Phasor Measurement (RPMF) and the R\&D of the Transformer Monitoring System (SMT), the case studies used in this paper.

These two projects were chosen as both were motivated by the breakdown of technological dependency and nationalization of solutions. In addition, they started with experimental development phases until reaching the pioneer batch phase and the installation of equipment in the industrial plant, thereby making them suitable for insertion in the market and showing them as case studies for the analysis of this article.

\section{Technology Readiness Level \& Innovation Chain}

In Brazil, the National Electric Energy Agency regulates and supervises activities in the scope of the generation, transmission, and distribution of electric energy and promoting R\&D Programs. In this context, in the year 2000, law no 9991/2000 was published, which requires electric energy concessionaires to invest part of their operating revenues in $R \& D$ projects so that these resources are managed by the project executor and applied to projects that are part of their annual R\&D programs [9].

After the law was created, it is possible to identify two moments that influenced the R\&D and innovation management models in electricity companies in Brazil. From 2000 to 2008, the first period is comprised until the revision of the ANEEL $R \& R \& D$ Program manual, being supported by the management of what was understood by companies as "'"'regulatory risk"'"'. The respective risk provided for punishment if the agency did not approve investments in research. In the second moment, after 2008, the program started to include innovation initiatives with the following changes, as presented by [10]:

- Elimination of ANEEL's pre-approval obligation for investments;

- Creation of three types of projects within the innovation cycle: prototypes, pioneering lot, and insertion in the market;

- Opportunity for appropriation by the concessionaires of the benefits resulting from the sale of new products;

- New form of project inspection with a focus on research results and not only on the physical and financial control of resources;

- Elimination and simplification of the periodicity of annual investment cycles.

All of these factors came to simplify the process, encourage companies to join, and increase investments. To classify the development stage of each project, two methodologies are adopted in a correlated way, 
namely: the TRL (Technology Readiness Levels) that measures the level of readiness for innovation, and the innovation chain proposed by the National Electric Energy Agency (ANEEL). According to ANEEL, every $R \& D$ project should be framed in its proposed phase of development within the innovation chain, which can be classified as directed basic research, applied research, experimental development, head series, pioneer lot or insertion in the market [11].

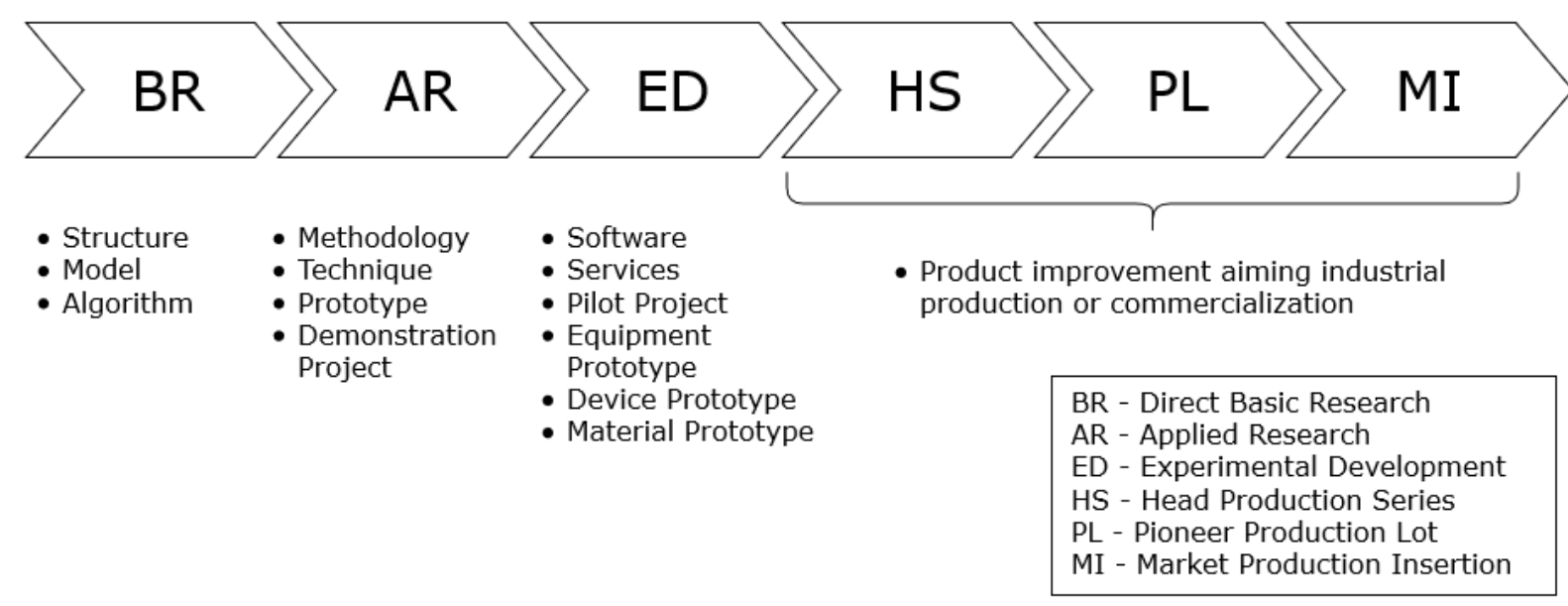

Figure 1. Innovation Chain (Adapted from ANEEL [1]).

Based on the innovation chain proposed by ANEEL, the results of an R\&D project vary depending on the nature, phase, or characteristics of the project. In terms of the main product, the result of a project classified as basic research can be a structure, a model, or an algorithm. The following products can be expected in the applied research phase: methodology or technique, proof of concept, or demonstrative project. In the experimental development phase, the following deliverables can be expected: software or services, which can be new or improved; implementation of a pilot project; prototype of equipment, device, or material. In the following stages, head series, pioneer batch, and insertion in the market, the product is expected to be improved with a view to industrial production or commercialization [11][12].

The adoption of this approach provides greater control of the necessary changes and optimization of decision-making between one phase and another to direct the innovation process in ways where the risks are lower and thus increase the chances of success of the project. Using the TRL methodology, Otto [13] relate the development phases of a project to levels of technological maturity, as described in the sequence and illustrated in Figure 2.

- TRL-1 - Basic principles observed and reported: corresponds to the lower level of technological maturation, being composed by basic research of scientific nature focusing on applied research and development;

- TRL-2 - Technology concept and/or application formulated: The results obtained in the previous level are applied on practical solutions. At this level, the application of the technology is still in the speculative stage of study, without experimental evidence to prove the concept;

- TRL-3 - Analytical and experimental critical function and/or characteristic proof-of-concept: Comprises both analytical and experimental approaches to the concepts studied at level TRL-2. This phase is characterized by the beginning of the applied research phase, where the concepts studied are tested and validated;

- TRL-4 - Component and/or breadboard validation in laboratory environment: validation in the laboratory through the use of simulators and the integration of individually tested components at the previous level in order to verify if they will be able to work together and thus make up the complete system, but without great fidelity to the system as a whole;

- TRL-5 - Component and/or breadboard validation in relevant environment: at this level the simulated test occurs in an environment very close to the real one, through the integration of the 
components in development. The tests are carried out in configuration with close proximity to the total application;

- TRL-6 - System/sub-system model or prototype demonstration in a relevant environment: at this stage the prototype, subsystem or component, in scale, goes through the performance tests in the real operating environment. It corresponds to an important step in development because it provides results regarding to behavior of the prototype or system under hostile operating conditions when integrated with other systems;

- TRL-7 - System prototype demonstration in the expect operational environment: demonstration in real environment of the prototype system operation. The prototype should be close to or in the real scale of the application for which it is intended;

- TRL-8 - Actual system completed and "'"'qualified"'"' through test and demonstration: represents the last stage of real system development. At this stage, the complete system undergoes demonstration tests in its operating environment. This level also involves technologies that will be integrated with systems already in operation;

- TRL-9 - Real system approved in the full range of expected conditions: operation of the approved technology in its operating environment.

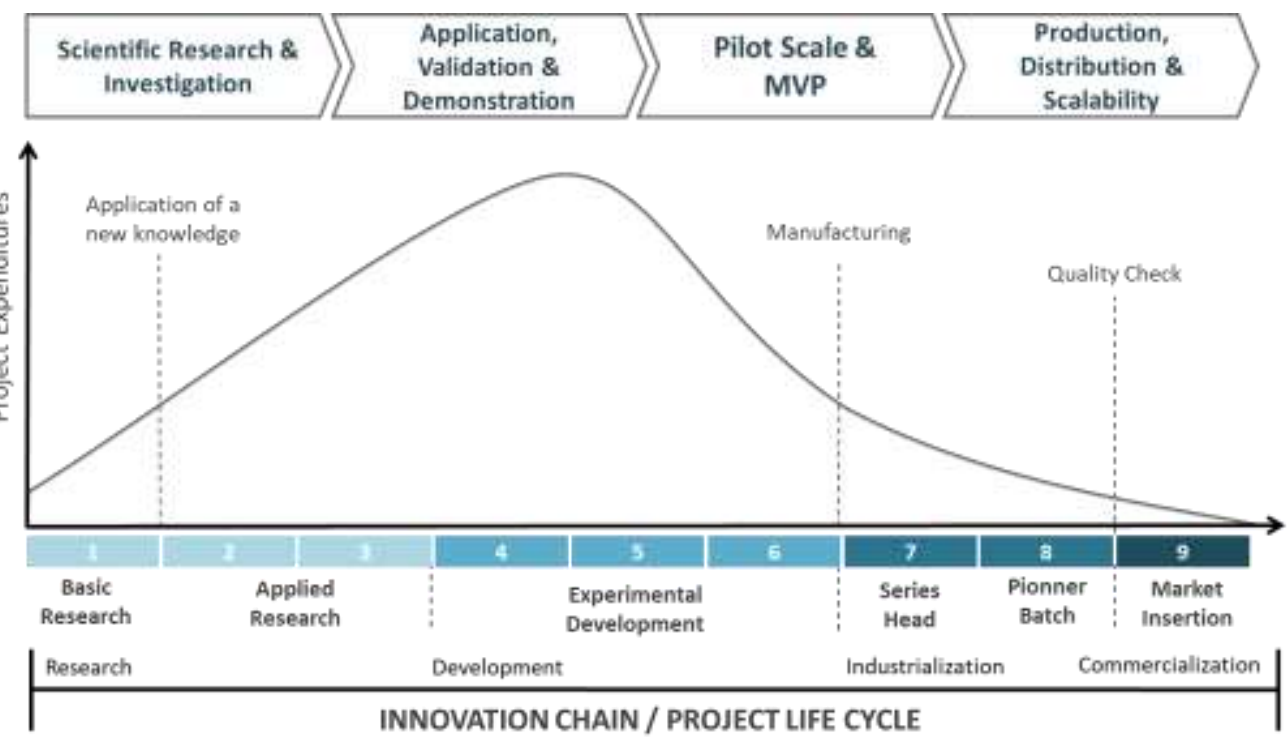

Description:

. Basic principles, models or algorithms Concept a/o application of technology Proof of concept or demonstration project

Functional werification of component $a / o$ subsystem in laboratory environment

. Checking the critical function of the component a/o subsystem in a relevant environment

6. Pilot project, prototype of the product $a / 0$ system in a relevant environment

Prototype demonstration of the product in an operational ervironment

Pilot scale, for testing and refinement of the actual product developed and approved

. Real system deweloped and approved through successful operations, and ready to market

Figure 2. Innovation Chain \& Project Life Cycle (R.Otto, Adapted from ABGI [4])

\section{Methodology}

This work is a case study for the instruction and application of the methodologies for classifying the maturity of R\&D projects. The development of this work was based on works previously developed by the works presented by [8], [12], [13] in which the projects under development were classified within both methodologies. Based on these works, projects with greater maturity were selected and presented in the results section as practical examples of success.

\section{Case Analysis}

The exact identification of the current stage of development of projects conducive to the manager helps in making decisions in the direction of human and financial resources, thus making the development of the project more fluid and efficient. Among the developed projects the Automation and Simulation Center, we have the aforementioned RPMF and SMT. These two projects went through the phases of the development cycle, starting with the development of the project in the laboratory (TRL 5), proceeding to the stage of installing the equipment in the field (TRL 7). With the equipment already installed and operating, it became opportune to start a third phase (TRL 8), which is based on product refinement. 
In the search for innovative solutions, Itaipu Binacional, through the Corporate University (UCI), presented the need for research that dealt with the Digital Fault Recorder (DFR) and Phasor Measurement Unit (PMU) functionalities.).

The solution presented was the RPMF system (Disturbance Recorder and Phasor Measurement), which enables the acquisition, monitoring, and recording of quantities associated with the electricity generation equipment at the ITAIPU plant.

Running since 2010, this project has the following main benefits:

- Reduces the cost of acquisition with the implementation of multifunction equipment: DFR + PMU = UMR (Measurement and Registration Unit), and also reducing the cost of cabling necessary for interconnection;

- Increase in the number of information available for fault diagnosis;

- Enables real-time monitoring of the electrical system conditions employing phasor measurement;

- Synchronized system (<100ns of precision) allows the comparison of oscillography records between different system points.

Among the project's functionalities, there is:

- Fault identification due to violation of upper and lower limits, upper variation, instantaneous variation, changing of the normal state, receiving external trigger via an optical signal, IEC 61850, GOOSE or Ethernet;

- Configuration of the entire data acquisition and fault detection system through a web interface;

- Generation and storage of oscillography records according to IEC C37.111-2011;

- Sending inter-triggers to other units;

- Measurement and phasor diffusion of 32 analog channels according to IEC C37.111-2011;

- Continuous data sending to the phasor concentrator and historical storage of information;

Regarding its software, the RPMF has its application divided into two modules, allowing the system configuration and download of records to be accessed via the web, besides allowing the visualization in instantaneous values, generation of manual events for tests, and status of the equipment.

As defined by ANEEL [2], Pioneer Batch is the phase that considers aspects related to production on a "'"'pilot scale"'"' of head series developed in a previous project. In this phase, first product manufacture or license reproduction is carried out on a "pilot scale" for validation tests, cost analysis, and project refining, with a view to industrial production and or, and project refining, with a view of industrial production and commercialization.

In this context, the RPMF project has gone through all phases of research, development, and head series from the beginning of its development. In 2014 October, as part of the planning for the development of the RPMF system, it was completed the assembly, installation, and field commissioning of the UMR-1415 panel (Measurement and Registration Unit), replacing in its entirety the DFR-1415 panel, and installing the CRF server ( Data Concentrator and Phasors) and PTP (Precision Time Protocol) time server.

With the installation of the UMR-1415 in the field, it emerged the opportunity to start a pilot-scale production of more units of the RPMF. The AS.DT has already supplied five other equipment units with an expected delivery of four more units in 2021.

\section{Transformer Monitoring System (SMT)}

The Itaipu Hydroelectric Plant (UHI) has twenty transformer banks responsible for elevating the voltage levels of each of the twenty generation units, from $18 \mathrm{kV}$ to $525 \mathrm{kV}$, with each bank consisting of three singlephase transformers.

In this architecture, each bank is individually monitored through a local panel, responsible for continuously collecting data from sensors installed in this equipment, allowing inferring in its operational condition. Although the current monitoring panels have communication with the SCADA system for the supervision of alarms, the collection of specific information is carried out only locally, creating the need for maintenance staff to acquire this data.

In this context, it emerged the proposal for the technological update of this monitoring system to facilitate access to information on the operational condition of transformers. Thus, the project's main objective is to integrate the panels of the 20 three-phase banks through the Integrated System of Industrial Networks (SIRI), 
with the already existing infrastructure, providing more agility to the maintenance staff in addition to a database for remote access. The project also includes new tools for failure analysis, contributing to improving the availability rates of the generating plant. Also noteworthy is the web interface for remote access where in addition to online viewing of all monitored variables, it allows the customization of diagnostic calculations and alarms according to the user's needs, thus expanding the potential of the monitoring system.

In addition to the creation of a system for the integration and centralization of transformers' information, the project also included the development of a solution for local monitoring, characterized by a panel that presents, among other features, the ability to acquire and treat sensor data, performing local calculations, storing data in case of connection loss to the server, generating alarms directly to SCADA or the web interface.

For that, two customized panels were produced to meet the real needs of the end-user, one for application in the $60 \mathrm{~Hz}$ sector and the other for the $50 \mathrm{~Hz}$ sector. With the installation of the project and the start of its operation at the plant in April 2016, the possibility of supplying transformer monitoring panels for the other eighteen units is envisaged to replace the currently installed monitoring panel. The technology used in this equipment is discontinued, which prevents new diagnostic tools based on algorithms that use, as a data source, quantities obtained online and continuously.

\section{CONCLUSION}

Innovation ecosystems are conducive environments for the development of innovative solutions. These sites bring together actors from different segments, including researchers, technicians, teachers, students, entrepreneurs, and investors. In addition, they have resources such as adequate infrastructure and equipment to boost research, development, and innovation [14].

Investing in research and development structures is the key to efficient production with competitive advantages, based on a continuous flow of innovative products and services [15]. According to [16], the challenge is not simply to add resources to the innovation system but to define how these resources are used through effective management of $R \& D+l$ that includes strategic direction, efficient communication, and maintenance, thus resulting in new business opportunities for an organization.

Through the expansion of solutions and the development of structuring projects to concentrate and integrate information, the final step will enable market study, patent registration, and partnership with companies for the technological transfer.

In conclusion, to advance in projects with a maturity level of TRL 9, it is recommended to enter the market with technology-based companies. Therefore, a specific business plan was carried out, with an operational, market, and financial feasibility study for the creation of a Spinoff in automation and instrumentation, operate in the industrial automation market and meet market demand with innovative products developed by research centers of the Itaipu Technological Park, which is a model that other scientific institutions can replicate.

\section{REFERENCES}

1. Weyer S, Schmitt M, Ohmer M, Gorecky D. Towards Industry 4.0 - Standardization as the crucial challenge for highly modular, multi-vendor production systems. IFAC-PapersOnLine. 2015;48(3):579-84.

2. Culot G, Nassimbeni G, Orzes G, Sartor M. Behind the definition of Industry 4.0: Analysis and open questions. Int. J. Prod. Econ. 2020;226:107617.

3. Kagermann H, Wahlster W, Helbig J. Recommendations for Implementing the Strategic Initiative Industrie 4.0. Final Report of the Industrie 4.0 Working Group Frankfurt [Internet]. National Academy of Science and Engineering. 2013 [cited 17 March 2021]. Available from: https://en.acatech.de/wpcontent/uploads/sites/6/2018/03/Final_report_Industrie_4.0_accessible.pdf

4. Wang S, Wan J, Zhang D, Li D, Zhang C. Towards smart factory for industry 4.0: a self-organized multi-agent system with big data-based feedback and coordination. Computer Networks. 2016;101:158-68.

5. Muscio A, Ciffolilli A. What drives the capacity to integrate Industry 4.0 technologies? Evidence from European R\&D projects. Econ. Innov. New Technol. 2019;29(2):169-83.

6. Yamada V, Martins L. Indústria 4.0: um comparativo da indústria brasileira perante o mundo. Revista Terra \& Cultura: Cadernos de Ensino e Pesquisa [Internet]. 2018 [cited 17 March 2021];34(0104-8112):95-109. Available from: http://periodicos.unifil.br/index.php/Revistateste/article/view/1011/947

7. Brasil. Agenda brasileira para a Indústria 4.0 [Internet]. 2018 [cited 17 March 2021]. Available from: http://www.industria40.gov.br/ 
8. Szollosi C, Otto R, Terada G. Estudo sobre o desenvolvimento de produtos em ambiente P\&D. International Symposium on Project Management, Innovation and Sustainability [Internet]. 2018 [cited 17 March 2021];VII(23178302):1-10. Available from: http://www.singep.org.br/7singep/resultado/357.pdf

9. Brasil. Lei No 9.991, de 24 de Julho de 2000 [Internet]. Presidência da República, Casa Civil, Subchefia para Assuntos Jurídicos. 2000 [cited 17 March 2021]. Available from: http://www.planalto.gov.br/ccivil_03/leis//9991.htm

10. Guedes C. An overview of the network for research and development (R\&D) on public policy of the Brazilian electricity sector. [Internet]. 2011 [cited 17 March 2021];:1-40. Available from: https://www.aneel.gov.br/documents/656835/14876412/Artigo_Clelia_Guedes.pdf/1f90946c-4ba8-4b94-93310540fcf93f20

11. ANEEL. Manual do programa de pesquisa e desenvolvimento tecnológico do setor de energia elétrica. 2012;.

12. Baez C, Otto R. O planejamento da inovação em projetos de P\&D: Estudo de caso do LASSE. Congresso Nacional de Excelência em Gestão [Internet]. 2014 [cited 17 March 2021];10(1984-9354):1-12. Available from: https://www.inovarse.org/sites/default/files/T14_0324_0.pdf

13. Otto R, Szollosi C, Terada G, Hisamura R, Zat G, Pereira J. Methodology for Product Development in R\&D Companies in Transdisciplinary Engineering for Complex Socio-technical Systems. Proceedings of the 26th ISTE International Conference on Transdisciplinary Engineering. 2019; 269-78.

14. Pereira J, Penha M, Júnior O, Otto R, Mognon V. New application of product development model oriented to the r\&d program of Brazilian electrical sector for planning a product project. Advances in Transdisciplinary Engineering [Internet]. 2018 [cited 17 March 2021];7:431-440. Available from: https://ebooks.iospress.nl/volumearticle/49825

15. Tidd J. Gestão da Inovação. 5th ed. Bookman; 2015.

16. Baez CA, Otto RB, da Silva FP, Dechechi EC. Technology roadmap applied in R\&D projects. Adv. Transdiscipl. Eng. 2019;10:279-88.

(C) 2021 by the authors. Submitted for possible open access publication under the terms and conditions of the Creative Commons Attribution (CC BY NC) license (https://creativecommons.org/licenses/by-nc/4.0/). 